\title{
Desempenho recente do mercado de trabalho brasileiro: 1992-2005
}

\section{LAURO RAMOS*}

Recent behavior of the Brazilian labor market: 1992-2005. This study aims at describing the behavior of the Brazilian labor market between 1992 and 2005. This period comprises significant changes in the economic scenario, in the midst of the process of opening the economy to adjust to the prevailing international economic order. In the one hand, the paper focuses on the time evolution of the main labor market indicators, trying to identify trends and stylized facts. On the other, it emphasizes aspects related to spatial patterns, particularly in terms of the metropolitan versus non-metropolitan behavior.

Keywords: labor market; employment and unomployment; time evolution; spatial realloction.

JEL Classification: J21; J23; J24.

\section{INTRODUÇÃO}

De forma simplificada, para fins ilustrativos, é possível admitir que são três os determinantes do desempenho do mercado de trabalho. O primeiro, de cunho mais estrutural e que acaba sendo o principal determinante da natureza do seu funcionamento, diz respeito às instituições que o regem - regulamentações e intervenções. $\mathrm{O}$ segundo, menos perene e mais sujeito a mudanças súbitas do que o anterior, são as condições macroeconômicas - do país e de fora dele - que ajudam a definir ou a delimitar a demanda por trabalho. O terceiro item está mais ligado à capacidade do mercado de trabalho de prover em grandezas absolutas valor. Aqui os componentes principais são a quantidade e a qualidade da força de trabalho, que vão definir em boa medida a sua capacidade produtiva. Embora as alterações recentes na dimensão

\footnotetext{
* Pesquisador do IPEA, com apoio do CNPq. E-mail: Lauro.ramos@ipea.gov.br. Submetido: Maio 2007; Aprovado Junho 2008.
} 
institucional tenham sido inexpressivas, o entorno econômico, o padrão demográfico e o quadro educacional experimentaram mudanças importantes. O propósito deste estudo é avaliar, com base nos dados da PNAD, do IBGE, como foi a evolução do mercado de trabalho no Brasil no período que vai de 1992 até 2005, que engloba a parte mais importante da transição de paradigma econômico em direção à abertura das fronteiras da economia, em consonância com a nova ordem econômica internacional. Um dos aspectos enfatizados é o contraste do comportamento dos mercados de trabalho metropolitano e não metropolitano, de forma a avaliar a representatividade da profusão de informações contemporâneas sobre o primeiro

Em 2005, segundo a PNAD, a PIA brasileira era de 150,2 milhões de pessoas, sendo 94,3 milhões na PEA e 55,9 milhões fora dela. ${ }^{1}$ A pesquisa do IBGE considera como ocupados e participantes do mercado de trabalho as pessoas que exercem atividades voltadas para o autoconsumo, construção para fins próprios, bem como qualquer tarefa não remunerada, independentemente da jornada de trabalho. Dada a natureza peculiar dessas atividades, que na verdade encerram uma ideia muito difusa de mercado, optou-se aqui por separá-las das demais, classificando as pessoas envolvidas com essas atividades como pertencentes à PEA marginal, desde que não tivessem procurado outra forma de ocupação na semana de referência da pesquisa, e as demais como pertencentes à PEA efetiva. Objetivamente, os conceitos de ocupação e desocupação utilizados foram:

Ocupados: foram classificados como ocupados na semana de referência os indivíduos que exerceram trabalho remunerado naquela semana, assim como os que exerceram trabalho não remunerado durante pelo menos 15 horas naquele período, e ainda os que tinham trabalho remunerado mas do qual estavam temporariamente afastados. Não foram considerados ocupados os indivíduos que exerceram trabalho para o próprio consumo ou construção própria na semana de referência.

Desocupados (ou desempregados): foram considerados como desocupados, ou desempregados, os indivíduos que não trabalharam, mas procuraram trabalho, na semana de referência. Também foram considerados desocupados os indivíduos que:

- exerceram trabalho não remunerado na semana de referência e trabalharam menos de 15 horas mas procuraram trabalho na mesma semana; e

- exerceram trabalho para o próprio consumo ou construção própria na semana de referência, mas procuraram trabalho na mesma semana.

Dessa forma, a PEA efetiva é dada pela soma de ocupados e desocupados, sendo que as pessoas envolvidas com as atividades marginais supracitadas e que não procuraram trabalho na semana de referência foram rotuladas como pertencentes à PEA marginal. ${ }^{2}$ Em 2005, o tamanho da PEA efetiva era de 89,8 milhões,

\footnotetext{
${ }^{1}$ Para preservar a possibilidade de comparação ao longo do tempo, esses números para 2005 não incluem as áreas rurais da região Norte, com exceção do Tocantins, que até 2003 não eram investigadas pela PNAD.

${ }^{2}$ A desconsideração do trabalho para autoconsumo e da construção para fins próprios como ocupação altera, é claro, a distribuição espacial em um instante de tempo qualquer, pois penaliza as áreas rurais.
} 
enquanto a PEA marginal era de 4,5 milhões de pessoas, das quais 3,5 milhões estavam envolvidas com atividades voltadas para o autoconsumo.

Assim, em 2005, a taxa de participação no mercado de trabalho, isto é, a parcela das pessoas elegíveis para participar do mercado de trabalho (PIA) e que de fato o fazem (PEA efetiva) ${ }^{3}$ foi de 59,8\%. ${ }^{4}$ A PEA em 2005 era composta de 80,6 milhões de pessoas ocupadas e 8,5 milhões de desempregados. Com isso, a taxa de desemprego nesse ano foi de 10,2 - utilizando o conceito de força de trabalho do IBGE ela seria de 9,7\%, um pouco menor em virtude de a PEA marginal ser considerada como população ocupada segundo aquele conceito. O fluxograma disponível na versão eletrônica da revista oferece uma exposição abrangente e detalhada da magnitude e composição atuais do mercado e trabalho brasileiro, que serão investigadas nas próximas seções.

\section{AVALIAÇÃO DO COMPORTAMENTO RECENTE DO MERCADO DE TRABALHO}

Por larga margem, o indicador mais utilizado para a avaliação do desempenho do mercado de trabalho é a taxa de desemprego. De modo geral, quando esse indicador se encontra em patamares baixos, a avaliação tende a ser de que o mercado de trabalho passa por um bom momento, ao contrário de quando ele passa para níveis mais elevados. Nesse sentido, o Gráfico 1 (na página seguinte) mostra a evolução da taxa de desemprego medida a partir da PNAD no plano nacional, indicando um progressivo desaquecimento desse mercado ao longo do período pós-Real até o ano de 1999, quando entra em um período de estabilidade.

Esse diagnóstico, mesmo que na maioria das vezes razoavelmente correto, pode eventualmente gerar equívocos, na medida em que a taxa de desemprego é um indicador sintético resultante de movimentos nem sempre em direções análogas, no sentido de não permitirem nenhuma conotação de ambiguidade para a sua indicação ou diagnóstico, às da oferta (PEA, taxa de participação) e da demanda por trabalho (nível da ocupação, geração líquida de postos de trabalho). Para facilitar a compreensão dessa relação e ilustrá-la para o passado recente, é conveniente apresentar uma maneira de visualizar essa evolução por intermédio de um diagrama de fases bastante simples. Para tanto, duas abstrações são necessárias:

a) admitir a existência de uma taxa natural, ou aceitável, ou desejável, ou tradicional, seja o que for, mas que sirva como referência para avaliar se o mercado de trabalho está tendo um bom desempenho sob esse prisma ou não; e

\footnotetext{
Não há razão, todavia, para que esse procedimento introduza viés no que tange a mudanças ao longo do tempo. De modo similar, as definições utilizadas para ocupação e desocupação tendem a elevar a taxa de desemprego em um determinado instante, mas não afetam a natureza das variações dessa taxa no tempo. Para maiores detalhes a respeito, ver Ramos \& Ferreira (2005).

${ }^{3}$ Doravante a PEA efetiva será chamada aqui simplesmente de PEA, por questões de simplicidade.

${ }^{4}$ Utilizando o conceito de força de trabalho do IBGE ela foi de $62,8 \%$.
} 
Gráfico 1: Evolução da taxa de desemprego (em \%)

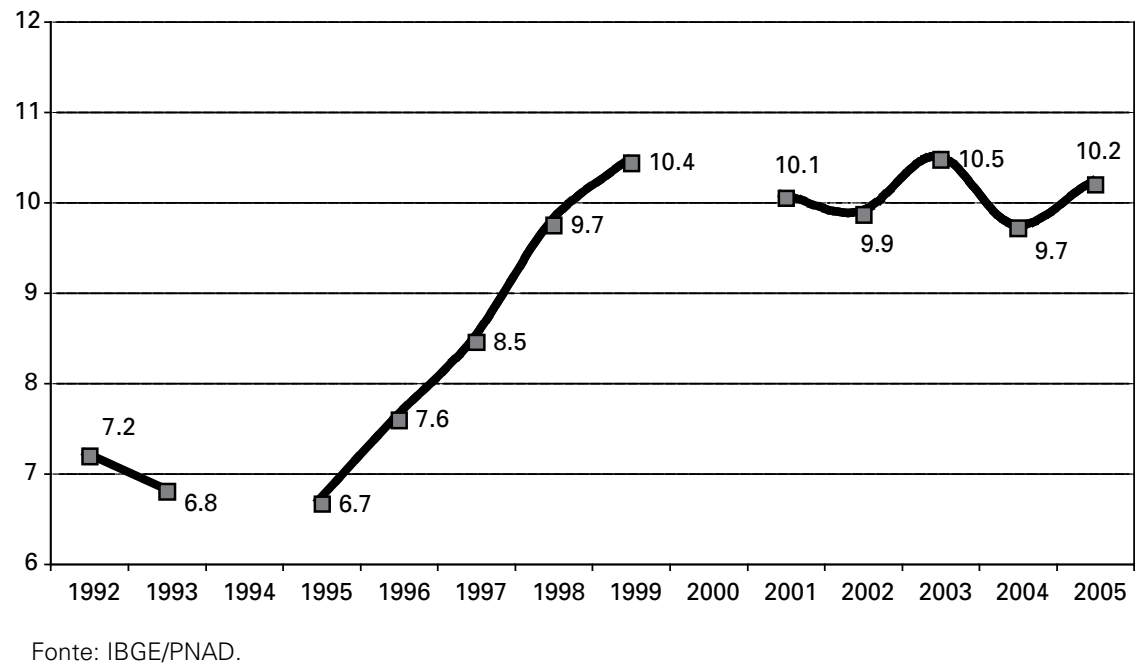

b) de forma análoga, pressupor a existência de uma taxa de participação normal, ou tradicional, de tal forma que patamares superiores a ela signifiquem uma pressão acima do normal sobre o mercado de trabalho em termos de geração de emprego - ocorrendo o contrário para taxas inferiores a essa referência.

Isso feito, é possível construir o diagrama de fases mostrado na Figura 1, grafando a taxa de desemprego no eixo vertical e a taxa de participação no eixo horizontal, ambos com centro nas taxas de referência aqui mencionadas. Dessa maneira são formados quatro quadrantes, que representam diferentes estados - ou desempenhos - do mercado de trabalho:

a) No quarto quadrante (abaixo e à direita) é possível afirmar que o mercado está em uma situação confortável, pois está mostrando um bom desempenho (a taxa de desemprego é inferior à usual, ou natural), ainda que com uma pressão da oferta acima do normal (a taxa de participação é a maior do que a usual), o que significa que ele está criando empregos em quantidade mais do que suficiente para absorver a oferta numa proporção aceitável, apesar de pressionado - existe, portanto, espaço para acomodar, pelo menos na margem, eventuais contratempos.

b) No primeiro quadrante ocorre o contrário: o mercado de trabalho está em uma situação desconfortável, uma vez que seu desempenho está aquém do aceitável (a taxa de desemprego é alta), mesmo sob uma pressão da oferta abaixo da usual (a taxa de participação é baixa), refletindo assim uma capacidade de geração de empregos bastante limitada. O mercado está debilitado e, portanto, é preciso uma melhora considerável para que a taxa de desemprego retorne para níveis toleráveis, principalmente se a oferta também voltar à normalidade.

c) No segundo e no terceiro quadrantes o diagnóstico é incerto, pois ou o mercado está tendo uma performance inferior à desejável, mas está sob pressão anormalmente elevada (segundo quadrante), ou está tendo um desempenho acima 
Figura 1: Estados do Mercado de Trabalho

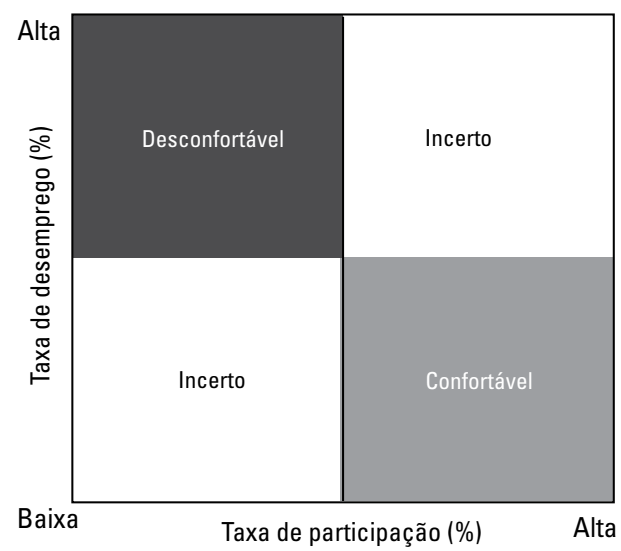

do habitual, mas em condições do lado da oferta mais favoráveis do que o normal (terceiro quadrante).

O diagrama a seguir mostra, de acordo com essa visão, o comportamento recente do mercado de trabalho nacional. Para construí-lo foram utilizadas como eixos centrais, de forma assumidamente arbitrária, as médias do período como referências para as taxas de desemprego e participação normais. ${ }^{5}$ Feita a qualificação, o diagrama revela que, na primeira metade dos anos 1990, o mercado de trabalho estava em uma situação relativamente confortável, apresentando taxas de desemprego baixas no contexto do período como um todo, mesmo sob pressão da oferta acima da média do intervalo analisado.

Figura 2: Estados do Mercado de Trabalho

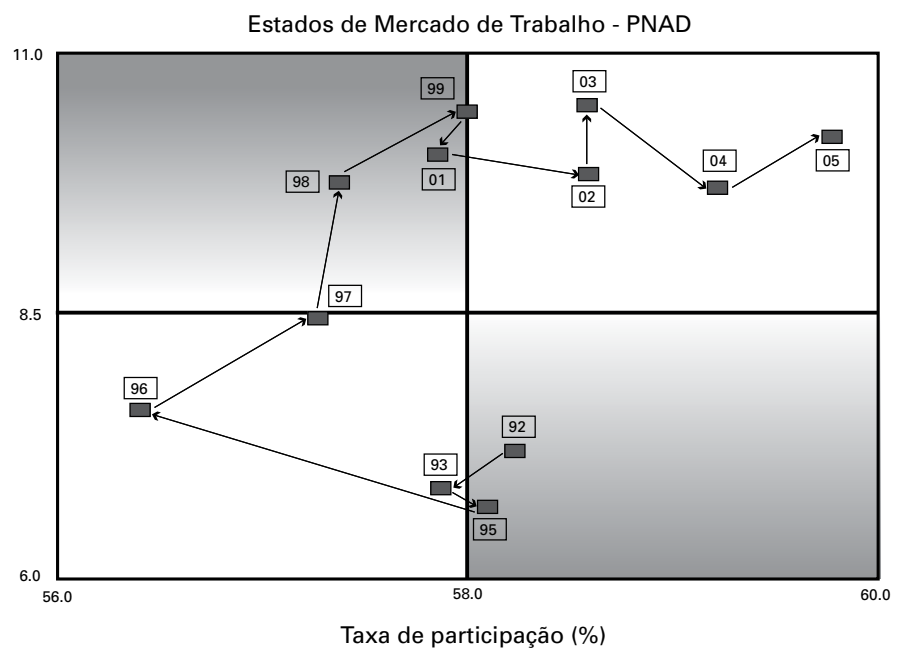

\footnotetext{
${ }^{5}$ De qualquer maneira a direção da trajetória, que indica a natureza qualitativa da mudança, não é afetada por essa escolha.
} 
Uma ligeira tendência de deterioração é revertida após a implementação do Plano Real, o que dura até 1995. Depois disso, a partir de 1996, ocorre um aumento da taxa de desemprego em meio à redução da taxa de participação. A deterioração torna-se mais flagrante em 1998, quando a súbita elevação da taxa de desemprego ante uma taxa de participação estável leva o mercado de trabalho uma situação de preocupação e desconforto (taxas de desemprego altas mesmo sob pressão da oferta abaixo do normal). Após a mudança do regime cambial a situação apresenta pequena melhora em 1999 e, provavelmente, ela teria sido mais acentuada em 2000 se houvesse dados da PNAD para esse ano. Após um breve retorno ao quadrante de desconforto em 2001, consequência dos efeitos do racionamento de energia sobre a economia e a geração de empregos, o mercado volta a melhorar paulatinamente, fixando-se no primeiro quadrante - a taxa de desemprego permanece razoavelmente estável, não obstante a presença de um contínuo aumento da pressão da oferta, que retorna aos níveis da década anterior.

Em suma, apesar de os movimentos serem parecidos com os da taxa de desemprego per se, e os estados inicial e final serem semelhantes, algumas transições específicas - 1998-1999 e 2001-2002, por exemplo - são bastante distintas. Vale notar também que, apesar de as taxas de desemprego serem quase iguais em 1999 e 2005, o diagrama indica que nesse ínterim houve uma melhora apreciável no mercado de trabalho. Essas avaliações diferentes em determinados momentos se devem, é claro, à combinação das dimensões da oferta e da demanda por trabalho, que serão examinadas mais detidamente a seguir.

\section{OFERTA DE TRABALHO}

A queda na taxa de fecundidade a partir dos anos 1980 fez com que em tempos recentes a taxa de crescimento da PIA entrasse em declínio, enquanto os reflexos no mercado de trabalho das mudanças por que passou a economia brasileira alteraram o processo de decisão de ingresso na força de trabalho. Paralelamente, movimentos que já se faziam sentir há mais tempo em decorrência do progressivo abrandamento de posturas discriminatórias e segregacionistas prosseguiram seu curso, resultando, por exemplo, em uma maior participação das mulheres no mercado. O resultado desses diversos fatores acaba por influenciar a taxa de participação e, consequentemente, a oferta de trabalho. Além disso, há elementos de ordem conjuntural, como os efeitos desalento e trabalhador adicional, que contribuem para afetar a taxa de participação e a pressão da oferta sobre os indicadores de desempenho.

As informações contidas na Tabela 1 ilustram com nitidez as mudanças potenciais na evolução da oferta de trabalho, advindas da mudança do padrão demográfico. Embora no período como um todo a PIA e a PEA apresentem crescimento não muito distinto ( $33 \%$ e $36 \%$, respectivamente), nesse mesmo período o ritmo de expansão da PIA diminui sobremaneira: de uma média de $2,3 \%$ a.a. na década de 1990 para 2,0\% a.a. na atual. A PEA, ao contrário, aumentou sua expansão de 


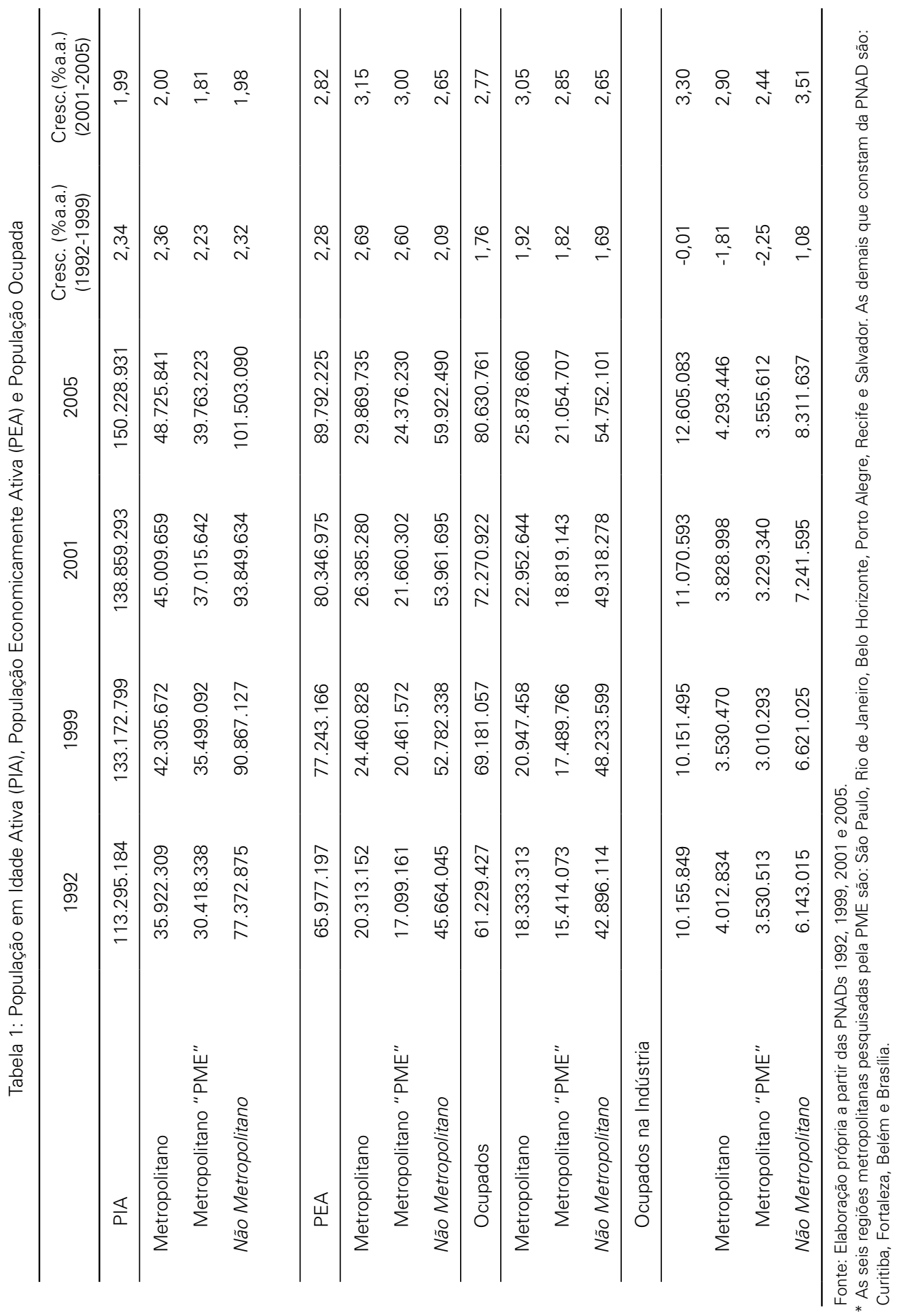


$2,3 \%$ para $2,8 \%$ nos dois períodos, reflexo do aumento da taxa de participação no início da década atual, retornando aos níveis do começo dos anos 1990. Um diagnóstico sobre os determinantes dessa reversão no comportamento da taxa de participação foge ao escopo desse estudo, mas, por certo, há um limite para o crescimento recente e, uma vez estabilizada, a diminuição da expansão da PIA será transformada em uma redução do crescimento da oferta de trabalho.

Vale destacar, enquanto a taxa de participação dos homens declinou de forma quase contínua, passando de 75,0\% em 1992 para 71,3\% em 2005, a participação feminina apresentou elevação de quase 7 p.p., passando de $42,4 \%$ para $49,1 \%$. Com isso aumentou a fração das mulheres na força de trabalho.

\section{OCUPAÇÃO}

Os dados sobre a evolução do nível da ocupação no período em foco, conforme retratado na Tabela 1, mostram um intervalo de quase estagnação entre 1995 e 1999, seguido de uma recuperação a partir de 2001. Fica claro então que em boa parte do período analisado a taxa de desemprego, na ausência de geração de empregos, foi comandada pelo comportamento da oferta, bem como pela atuação no sentido de atenuar as variações da demanda em 1999 e em 2001. Neste último em particular, a taxa de desemprego provavelmente teria sido substantivamente mais alta não fosse a queda observada na pressão da oferta, conforme identificado no diagrama de fases anteriormente discutido. Há uma nítida diferença no padrão de evolução da ocupação nas décadas anterior e atual, com as taxas médias de crescimento subindo de forma expressiva de 2001 para cá tanto nos mercados de trabalho metropolitanos quanto, principalmente, fora deles, de tal forma que no plano nacional ocorre um salto de $1,8 \%$ a.a. para $2,8 \%$ a.a. de um período para outro.

A população ocupada total teve um crescimento de $31,7 \%$, passando de 61,2 milhões em 1992 para 80,6 milhões em 2005, o que significa a geração de 17,5 milhões de postos de trabalho em termos líquidos. Em termos espaciais esse aumento esteve mais concentrado em algumas áreas e regiões do que em outras. Esse é o caso, por exemplo, das áreas metropolitanas vis-à-vis as não metropolitanas. Enquanto as seis RMs pesquisadas pela PME experimentaram um aumento de aproximadamente $36,6 \%$ (o equivalente a cerca de 5,6 milhões de ocupados), ${ }^{6}$ percentual pouco inferior ao agregado das dez metrópoles brasileiras $(41,2 \%-$ equivalente a 7,5 milhões de ocupados), o Brasil não metropolitano apresentou um crescimento de $27,6 \%$ (o equivalente a 11,98 milhões de ocupados). Como resultado desse crescimento diferenciado, as áreas metropolitanas aumentaram sua participação na ocupação total em 2,2 p.p. - o subconjunto da PME, considerado isoladamente, aumentou sua participação em cerca de 0,9 p.p.

É importante chamar a atenção para o fato de que o menor crescimento da ocupação não metropolitana é decorrência direta do desempenho nas áreas rurais,

\footnotetext{
${ }^{6}$ É importante frisar que esses números são gerados a partir das próprias PNADS para as seis regiões da PME.
} 
nas quais ocorreu um encolhimento de 15,8\% nesse período de 13 anos. De fato, se tomada apenas a parte urbana das áreas não metropolitanas, observa-se uma geração expressiva de ocupações - foram criados 14,2 milhões de postos de trabalho entre 1992 e 2005, o que significa uma expansão de 49,2\%. Tal crescimento implicou um aumento na participação de 6,2 p.p., fazendo com que esta passasse a ser superior a $50 \%$ da ocupação nacional em $2005 .^{7}$

\section{Ocupação na Indústria}

Um segmento emblemático é o setor da indústria, por ser tradicionalmente encarado como segmento líder e indutor do processo de desenvolvimento econômico. O crescimento do emprego industrial se deu de forma relativamente tímida no período aqui examinado, tendo passado de 10,2 milhões de postos de trabalho em 1992 para 12,6 milhões em 2005, como também pode ser visto na Tabela1. Isso representa um crescimento de $23,5 \%$, inferior aos $31,7 \%$ constatados para a ocupação como um todo. A criação de empregos na indústria respondeu, assim, por apenas $12,9 \%$ do total de novos postos de trabalho. Esse resultado não chega a constituir surpresa, haja vista o processo de reestruturação e enxugamento da estrutura produtiva do setor para a obtenção de ganhos de produtividade e, assim, lograr maior competitividade internacional em um contexto de uma economia em franco processo de abertura. Tanto é que o ganho automático de competitividade proporcionado pela mudança de regime cambial, com consequente desvalorização da nossa moeda, funcionou como um divisor de águas para o desempenho do emprego na indústria: no período 1992-1999 o crescimento anual médio foi nulo, e passou para 3,3\% a.a. na década presente; o contraste é ainda mais intenso para as metrópoles, que haviam experimentado uma redução desse tipo de emprego na década anterior, passando a crescer na atual. ${ }^{8}$

\section{DESEMPREGO}

A taxa de desemprego, já discutida brevemente, após ligeira queda no período imediatamente pós-Real passou por um período prolongado de ascensão contínua (1996 a 1999), quando foi cunhada a expressão desemprego estrutural, que estaria associado às mudanças na estrutura produtiva ditadas pela nova ordem econômica internacional em que o Brasil se inseria no bojo do processo de abertura econômica. Independentemente da adequação desse diagnóstico, o fato é que após a mudança do regime cambial houve uma reorganização do processo produtivo e, na

\footnotetext{
${ }^{7}$ Dados disponíveis mediante solicitação.

${ }^{8}$ Ramos (2007), com base na Rais, e Ramos \& Ferreira (2005), com base na PNAD, investigam com mais detalhe a ocupação formal e total, respectivamente, na indústria e concluem que houve um processo de despolarização na década anterior, caracterizado por uma migração de postos de trabalho das RMs de São Paulo e Rio de Janeiro para áreas não metropolitanas.
} 
década atual, a taxa de desemprego vem se mostrando bem mais estável, em patamar pouco inferior ao atingido em 1999.

Uma hipótese bastante aventada durante o período de crescimento da taxa de desemprego é que o fenômeno era típico, e mais flagrante, nas grandes metrópoles. Como as taxas de desemprego da PME, em função da periodicidade e contemporaneidade dessa pesquisa domiciliar, tinham um impacto bastante forte na formação de opiniões e expectativas da sociedade em geral e agentes econômicos em particular, caso a hipótese fosse verdadeira, o diagnóstico daí inferido a respeito do dinamismo do mercado de trabalho poderia estar seriamente equivocado.Os dados da Tabela 2 indicam, todavia, que tais preocupações eram improcedentes, pois embora as taxas metropolitanas sejam, de fato, mais elevadas, as variações tendem a ser bastante similares. Em outros termos: se havia discrepâncias nas taxas da PME, elas se deviam à natureza da pesquisa, mas não eram decorrência da sua cobertura propriamente dita.

Voltando a atenção para aspectos de natureza mais qualitativa, entre as várias mudanças no funcionamento do mercado de trabalho nacional a partir dos anos 1990 que implicaram rupturas no padrão histórico, um dos fenômenos mais marcantes, e que mais atenção despertou entre especialistas e sociedade em geral, foi a proliferação das práticas informais em termos da inserção no mercado de trabalho, normalmente associadas à precarização da qualidade do trabalho, fragilização da inserção no mercado e banalização dos vínculos empregatícios. A definição de informalidade adotada aqui será aquela predominante na literatura, que considera como pertencentes ao setor informal o contingente de trabalhadores que não estão ao abrigo da proteção da legislação trabalhista - assalariados sem carteira e trabalhadores por conta própria. ${ }^{9}$

As informações contidas na Tabela 2 mostram que a percepção bastante disseminada de que houve um aumento substantivo do grau de informalidade ao longo dos anos 1990 se deve basicamente ao seu comportamento no âmbito metropolitano, de maior conhecimento e repercussão, dada a atualidade e frequência da PME, que, como já dito aqui, acaba por afetar sobremaneira as impressões e a formação de juízos. É fato que, no âmbito da PNAD, existe uma elevação de quase 6 p.p. (de $38,3 \%$ para $44,1 \%$ ) na informalidade metropolitana no período. Todavia, nas áreas não metropolitanas há redução de cerca de 4 p.p. (de 58,5\% para $53,7 \%$ ) desse indicador entre 1992 e 2005 , de modo até marcante nos últimos dois anos da série (era 56,4\% em 2002). A combinação desses movimentos convergentes entre o grau de informalidade metropolitano e não metropolitano assegurou uma estabilidade da informalidade do mercado como um todo e, mais recentemente, acarretou uma ligeira tendência de redução - em 1992 o percentual de informalidade era de 51,9\%, atingiu 53,5\% em 1999, voltando a 51,7\% em 2003 e caindo para $50,4 \%$ em $2005 .{ }^{10}$

\footnotetext{
${ }^{9}$ Ver Camargo (1989) para uma apresentação e discussão de visões alternativas.

${ }^{10}$ É importante destacar que a informalidade metropolitana, de acordo com as informações da PME, caiu ao longo de 2005 e início de 2006, o que torna lícito esperar uma queda mais apreciável no plano nacional em 2005.
} 


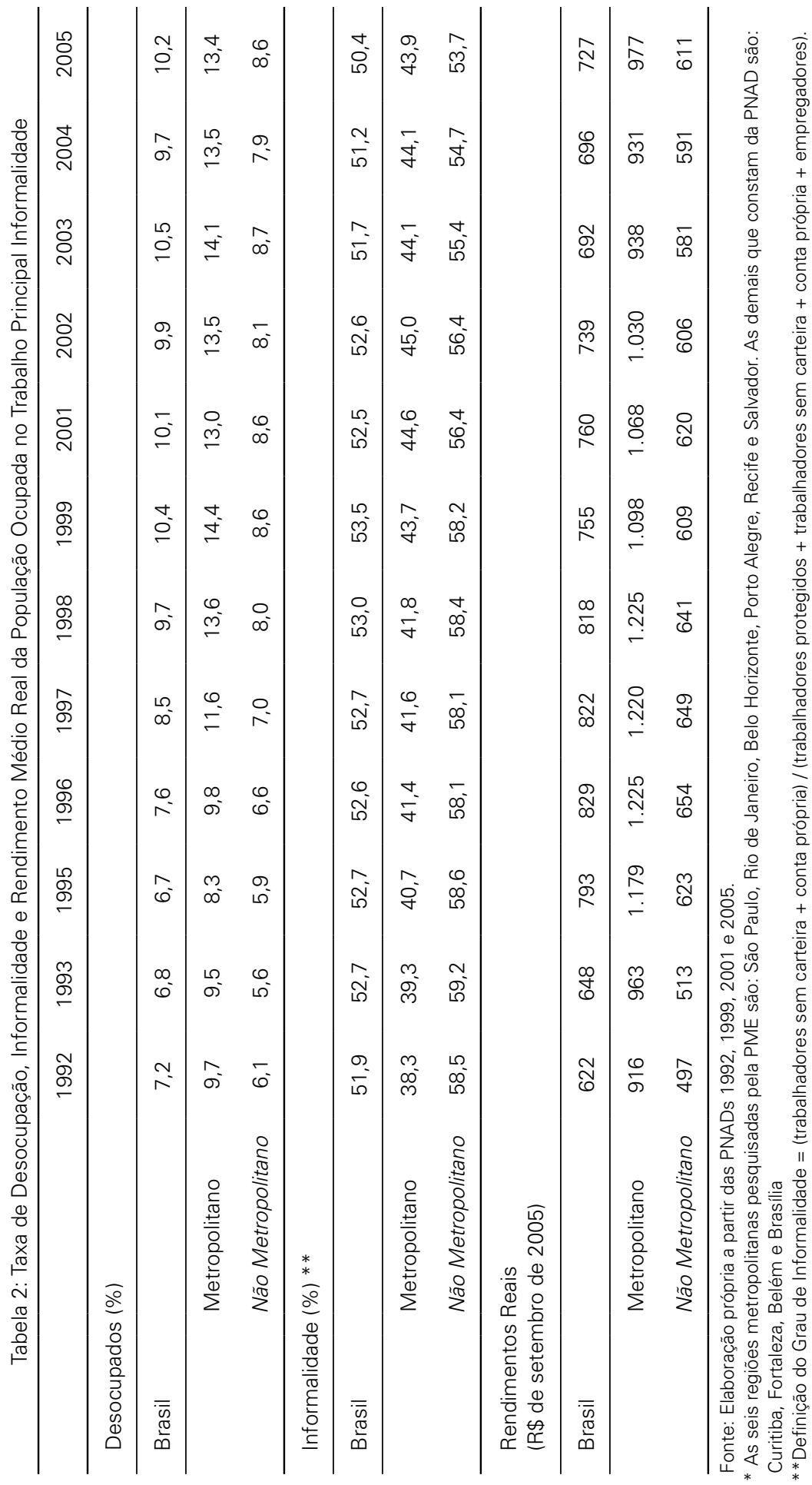


O fato de o grau de informalidade ter ficado constante no mercado de trabalho nacional pode, é verdade, trazer uma conotação de alívio, mas por si só não constitui necessariamente boas notícias. É preciso levar em conta que o patamar dessa estabilidade é bastante elevado, de tal sorte que pouco mais da metade da força de trabalho ocupada está inserida no setor informal e, além de não haver queda no agregado, é significativo o crescimento das práticas informais no âmbito das RMs. É fundamental ter clara a gravidade da situação, até porque algumas vezes a informalidade é defendida como "uma solução, e não um problema". É importante destacar aqui: boa parte da informalidade - o assalariamento sem carteira - é, na verdade, ilegalidade, visando ao não pagamento de encargos. Adicionalmente, o trabalho autônomo, o outro componente do contingente de trabalhadores do setor informal, por vezes é sinônimo de trabalho precário, resultado de uma estratégia de sobrevivência em circunstâncias em que o mercado de trabalho não consegue gerar empregos com um mínimo de qualidade em quantidade suficiente, e com características adequadas aos seus atributos/dotações/habilidades. Nesses termos, é difícil aceitar a tese da informalidade como solução. Mais apropriado parece, seria caracterizá-la, ao menos parcialmente, como grande reveladora da gravidade do funcionamento deficiente do mercado de trabalho, seja por questões mais conjunturais ligadas ao desempenho econômico ou, mais preocupante, como decorrência de inflexibilidades e custos introduzidos pela legislação trabalhista e demais instituições que o afetam, além da carga tributária excessiva.

\section{RENDIMENTOS}

A trajetória de evolução dos rendimentos reais médios a partir dos anos 1990 apresenta uma gama de variações e comportamentos. O advento do Plano Real em $1994 \mathrm{fez}$ com que os rendimentos médios do trabalho principal ${ }^{11}$ subissem quase $22 \%$ em dois anos, saltando, em valores de setembro de 2005, de R \$ 648 em 1993 para R 793 em 1995. ${ }^{12}$ Essa foi, por assim dizer, uma espécie de fase áurea daquele plano. No triênio que se seguiu, houve uma alta bem menos pronunciada em 1996 para um patamar que se manteve em 1997 e 1998, seguido de declínio em 1999 bem acentuado, aliás, nas RMs.

Até esse ano o comportamento no Brasil metropolitano e não metropolitano vinha sendo muito parecido. Dali em diante a tendência de queda foi mais presente nas RMs, que, entre 1998 e 2005, experimentaram uma redução de mais de $11 \%$ nos rendimentos reais do trabalho principal. Enquanto isso, a queda nas áreas não metropolitanas ficou limitada a 5\%. Mais importante, todavia, é que em 2004 a

\footnotetext{
${ }^{11}$ Enfocaremos aqui os rendimentos do trabalho principal, mas cabe ressaltar que comportamento e variações observados para o rendimento de todos os trabalhos foram bastante similares.

12 Esse talvez seja o indicador agregado para o qual a inexistência da PNAD em 1994 mais se faça sentir.
} 
PNAD indicou uma leve recuperação nessas últimas áreas e uma forte desaceleração no ritmo da queda observado nas RMs até então.

No caso das desagregações dos rendimentos segundo gênero e escolaridade, que são importantes por estarem associadas à iniquidade distributiva via desigualdade de tratamento e oportunidades, a evolução no período recente é um tanto alentadora. ${ }^{13}$ Após um pico em 1993, foram reduzidos tanto os diferenciais de rendimentos dos homens em relação às mulheres quanto os dos grupos mais escolarizados em relação aos trabalhadores com no máximo três anos completos de estudo. Os diferenciais por gênero, que eram de 80,5\% em 1993, vieram diminuindo de forma paulatina até atingirem $46,9 \%$ em $2005 .{ }^{14} \mathrm{O}$ padrão temporal do estreitamento dos diferenciais por escolaridade foi diferente, na medida em que a redução foi bem mais concentrada na década atual. Tomando como exemplo o rendimento dos trabalhadores ocupados que tinham pelo menos o segundo grau completo, o diferencial em relação ao grupo com no máximo três anos de estudo chegou a 462\% em 1993, tendo caído para 414\% em 1999 e $291 \%$ em 2005.

A redução dos retornos à escolaridade, bem como a progressiva eliminação de distorções de remuneração potencialmente associadas a práticas discriminatórias têm, por certo, efeitos benignos em termos de promoção de igualdade na distribuição de rendimentos no âmbito do mercado de trabalho. De fato, eles já vêm se fazendo sentir em termos da desigualdade da distribuição dos rendimentos individuais e, na década atual, também no que se refere à distribuição dos rendimentos (do trabalho) familiares per capita, conforme mostrado no Gráfico 2.

Gráfico 2: Desigualdade de Rendimentos do Trabalho - Coeficiente de Gini

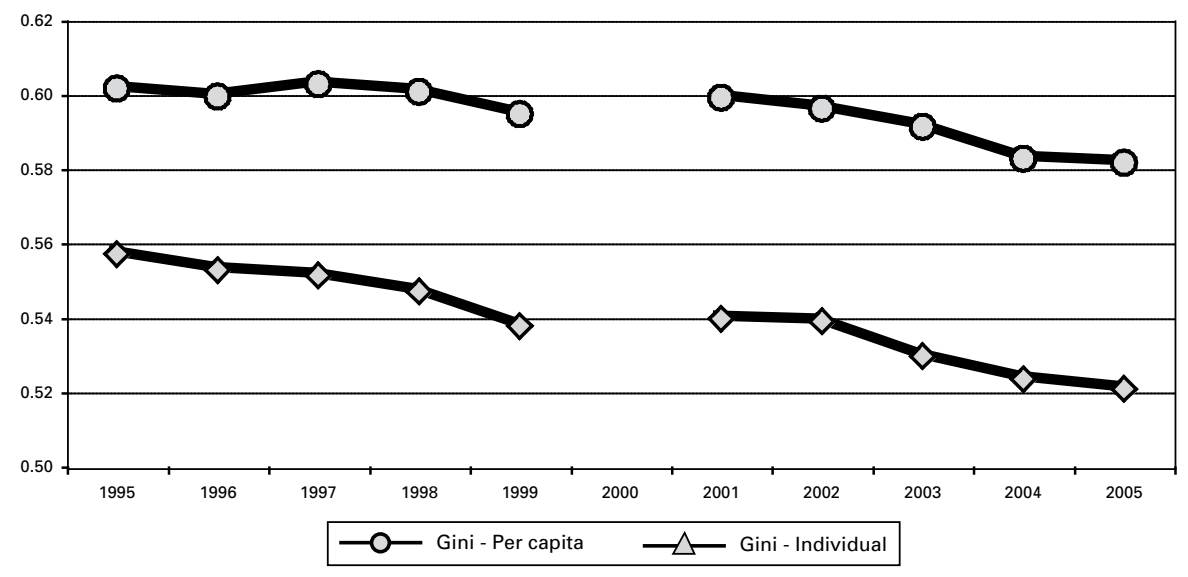

Fonte: IBGE/PNAD.

\footnotetext{
${ }^{13}$ Dados disponíveis na versão eletrônica da revista.

${ }^{14}$ Cumpre lembrar que esse é o diferencial bruto, sem levar em conta, por exemplo, o fato de as mulheres estarem sobrepujando os homens em nível de instrução, o que torna a situação ainda mais díspar.
} 
O coeficiente de Gini para a distribuição individual dos rendimentos totais do trabalho, tendo como universo os trabalhadores ocupados com rendimentos positivos, diminuiu de 0,557 para 0,538 entre 1995 e 1999 e, depois de subir, voltou a se reduzir de 0,540 para 0,521 entre 2001 e 2005 . No primeiro período a queda na distribuição individual não se refletiu na distribuição familiar per capita dos rendimentos do trabalho, cujo coeficiente de Gini ficou praticamente estável em torno de 0,600. Nos anos recentes a queda estendeu-se também a essa distribuição, com o Gini passando de 0,599 em 2001 para 0,582 em 2005.

Esse comportamento ligeiramente diferenciado das duas distribuições nos dois períodos, sem dúvida, desperta a atenção. Vale lembrar que, entre 1995 e 1999 a taxa de desemprego cresceu de forma palpável e continuada, tendo se estabilizado no patamar em torno de $10 \%$ entre 2001 e 2005, conforme mostrado no Gráfico 1. Essa constatação é sugestiva de que o aumento do desemprego no final da década passada ocorreu mais intensamente nas famílias mais pobres, de forma a anular os progressos distributivos observados nos rendimentos individuais. No período mais recente, contudo, esses progressos foram transmitidos à distribuição familiar per capita. Como o trabalho é a principal fonte de renda captada nas PNADs, eles acabaram por impactar a distribuição de renda como um todo que, conforme documentado em Barros et al. (2007)), ${ }^{15}$ atingiu o menor nível de desigualdade desde que a PNAD começou a ser coletada.

\section{SÍNTESE E CONCLUSÃO}

Ao longo do estudo ficou claro que a realidade do funcionamento do mercado de trabalho no final da década anterior foi bastante distinta daquela que prevaleceu na atual. No primeiro período a ocupação crescia de forma claudicante, havendo uma virtual estagnação no segmento da indústria, a informalidade aumentava e os rendimentos, após a formidável elevação nos anos que se seguiram à implementação do Plano Real, experimentavam sucessivas quedas: o mercado de trabalho passava por um claro quadro de deterioração, tanto do ponto de vista quantitativo quanto qualitativo. No período mais recente a geração líquida de postos de trabalho cresceu de forma apreciável, inclusive no âmbito da indústria, com os vínculos formais liderando o processo e acarretando uma reversão na evolução da informalidade, em meio a uma recuperação, ainda que segundo um padrão suave, dos rendimentos reais: o mercado de trabalho experimentava uma trajetória de franco reaquecimento.

Conforme visto na segunda seção, a taxa de desemprego - por larga margem o indicador mais utilizado para a avaliação do desempenho do mercado de trabalho - captou bem as dificuldades do primeiro período e aumentou de forma expressiva, principalmente de 1995 em diante, quando passou 6,7\% para 10,4\% em 1999.

\footnotetext{
${ }^{15}$ Essa coletânea discute minuciosamente o comportamento recente da desigualdade de renda no Brasil, destacando possíveis causas e implicações para o bem-estar social.
} 
$\mathrm{Na}$ década atual, todavia, a despeito da série de evidências em favor de uma melhora de desempenho, ela manteve-se estável para todos os fins práticos, oscilando timidamente em torno da marca de $10 \%$. A razão de ser desse descompasso reside no fato de que a taxa de desemprego é um indicador sintético que resume alterações de oferta e demanda por trabalho, que nem sempre atuam no mesmo sentido, podendo até se neutralizar. A contribuição desse estudo em termos de prisma analítico para a avaliação do estado do mercado de trabalho foi a introdução do diagrama de fases discutido na segunda seção, que contrapõem a taxa de desemprego com a taxa de participação, explicitando a dimensão da oferta.

Dessa forma, conforme mostrado na Figura 2, fica claro que o mercado de trabalho passou de uma situação confortável - taxas de desemprego relativamente baixas mesmo com maior pressão da oferta, conforme refletido por taxas de participação acima da média - para uma posição de maior dificuldade e desconforto - taxas de desemprego mais elevadas mesmo com menor pressão da oferta. Naturalmente o fator implícito, a demanda por trabalho, provê a explicação para tal movimento. O diagrama permite também identificar que na década corrente o mercado de trabalho deixa para trás a região de desconforto, caminhando do segundo para o primeiro quadrante, onde as taxas de desemprego são mais elevadas que o usual, assim como a pressão da oferta: a taxa de desemprego não cedeu, basicamente porque o aumento da oferta neutralizou a retomada da capacidade de geração de postos de trabalho.

Por fim, um aspecto investigado no estudo através da comparação do comportamento do mercado de trabalho metropolitano com o não metropolitano diz respeito à representatividade nacional dos dados contemporâneos disponíveis para o primeiro, que balizam as análises da conjuntura macroeconômica. A conclusão é que para os grandes agregados, como o nível de ocupação, bem como rendimentos e taxa de desemprego, as informações para o universo metropolitano fornecem uma boa indicação a respeito do desempenho no plano nacional. Há que tomar cuidado, todavia, quando o foco de interesse está em variáveis mais desagregadas, como o tipo de ocupação, pois o emprego industrial metropolitano teve um padrão bastante distinto daquele para o resto do país, bem como o emprego formal, conforme refletido na evolução assimétrica da informalidade dentro e fora das grandes metrópoles.

\section{REFERÊNCIAS BIBLIOGRÁFICAS}

BARROS et al (org.). Desigualdade de Renda no Brasil: uma análise da queda recente. Brasília: IPEA, 2007.

CAMARGO, J. M. Informalidade e renda no mercado de trabalho. In: SEDLACEK, G.; BARROS, R. (org.). Mercado de Trabalho e Distribuição de Renda: uma coletânea. Rio de Janeiro: IPEA, 1989.

RAMOS, L. Evolução e Realocação do Emprego Formal. Econômica, Rio de Janeiro, v. 9, n.1, 2007.

RAMOS, L. \& FERREIRA, V. Geração de empregos e realocação espacial no mercado de trabalho brasileiro: 1992-2003. Pesquisa e Planejamento Econômico, Rio de Janeiro, v. 35, n. 1, pp. 1-31, 2005. 